\title{
THERMOECONOMIC ANALYSIS AND MULTI-OBJECTIVE OPTIMIZATION OF AN INTEGRATED SOLAR SYSTEM FOR HYDROGEN PRODUCTION USING PARTICLE SWARM OPTIMIZATION ALGORITHM
}

\author{
Sajjad Keykhah¹, Ehsanolah Assareh¹, Rahim Moltames ${ }^{2,}{ }^{*}$, Abbas Taghipour ${ }^{1}$, Hassan Barati ${ }^{3}$
}

\begin{abstract}
This study aims to investigate the hydrogen production process using an integrated system based on solar energy. This system includes an evacuated tube collector to absorb solar energy as input energy of the system. A parametric analysis was conducted to determine the most important design parameters and evaluate these parameters' impact on the system's objective functions. For identifying the optimum system conditions, multi-objective optimization was performed using particle swarm optimization (PSO) algorithm. The results obtained from the parametric analysis show that an increment in the collector mass flow rate and the turbine inlet temperature, as well as a decrement in the collector area and the evaporator inlet temperature, results in improving the system exergy efficiency. Furthermore, the optimization results demonstrate that the exergy efficiency of the system can be improved from $1 \%$ to $3.5 \%$; however, this enhancement in exergy efficiency of the system leads to increase the system costs from $20 \$ / \mathrm{h}$ to $26 \$ \mathrm{~h}$, both at optimum states. At the optimum point, the average values for other performance parameters affecting the objective function including total output power production, cooling capacity, and hydrogen production rate are obtained as $24.24 \mathrm{~kW}, 47.07 \mathrm{~kW}$, and $218.56 \mathrm{~g} / \mathrm{s}$, respectively.
\end{abstract}

\section{Keywords: Multi-objective Optimization, Integrated Solar Energy System, Hydrogen Production, PSO}

\section{INTRODUCTION}

Depletion of the fossil fuel resources has compelled human society to explore alternative fuels. In recent years, renewable energy systems have been introduced as a solution for the energy generation challenges. Because of their comparably higher efficiency and non-polluting characteristics, these systems are considered as appropriate solutions for environmental pollution bottlenecks, too. Among the renewable energy resources, solar energy is one of the most promising renewable energy resources for application in different areas. Moreover, hybrid systems recently have been utilized to generate different energy forms simultaneously such as electrical and thermal energy, to produce new energy carriers like hydrogen. Regarding population growth, enhanced human life standards, and increased level of $\mathrm{CO} 2$ emissions, clean and eco-friendly fuels have attracted a lot of attention. In this regard, many researches have attempted to produce hydrogen using renewable energy resources. Some research papers which investigated the integrated system components including the organic Rankine cycle (ORC), flat plate solar collector, absorption chiller, and hydrogen production unit have been summarized below:

Luminosu et al. [1] optimized economy of a flat plate solar collector with this assumption that the the collector total heat loss coefficient and all other heat transfer coefficients are constant. Syed et al. [2] investigated several flat plate solar collectors to provide energy for a single-effect absorption chiller (35 kW), in Madrid, Spain. They reported a maximum spontaneous chilling efficiency of 0.6 , an average daily efficiency of 0.42 , and a cycle efficiency of 0.34. Sahoo [3] analyzed the exergy and economy of a homogeneous system to produce electricity and saturated steam, and finally, optimized the mentioned system using an evolutionary algorithm. They showed that the electricity and production costs can be reduced $9.9 \%$ by optimizing the system and using it at the optimum conditions. Yamada et al. [4] devised a conceptual design of a hybrid Rankine cycle system using solar and ocean thermal energies to improve the system efficiency. Mateus and Oliveira [5] simulated a solar heating and absorptive chilling system using two flat plates and analyzed solar tube collectors for a house, a hotel, and an office, in three This paper was recommended for publication in revised form by Regional Editor Assunta Andreozzi

${ }^{1}$ Department of Mechanical Engineering, Dezful Branch, Islamic Azad University, Dezful, Iran

${ }^{2}$ Department of Energy Engineering, Energy Systems Engineering, Sharif University of Technology, Tehran, Iran

${ }^{3}$ Department of Electrical Engineering, Dezful Branch, Islamic Azad University, Dezful, Iran

*E-mail address: rahim.moltames89@gmail.com

Orcid id: 0000-0002-6068-8850, 0000-0001-8203-8886, 0000-0001-9975-9049,0000-0002-1225-6594, 0000-0002-3893-5018

Manuscript Received 28 March 2019, Accepted 24 June 2019 
different European cities, using TRNSYS software. Two different configurations were used in their simulation. In the first configuration, a gaseous heater was utilized as the auxiliary device of the solar absorption chiller. The second configuration had the benefit of an electric compression chiller as the auxiliary system. Both configurations were evaluated from economic and energy perspectives to determine the minimum size of the collector and the reservoir, the cost of collector provision, and the cost of energy consumption to reach a 0.6 solar contribution. Villar et al. [6] simulated a solar absorption chilling and heating system with a nominal absorption chiller capacity of $10 \mathrm{~kW}$ which included a flat plate collector, using TRANSYS software. They used an electric compression chiller and an electric thermal pump as the auxiliary system for the chilling and heating seasons, respectively. They employed warm and cold water reservoirs in different parts of the system to evaluate the chilling and heating system in various modes and investigated the effect of the collector area and reservoir volume on solar contribution. Wang et al. [7] suggested a trigeneration system that worked with solar energy as the primary generator. They considered the exergy efficiency as the objective function and optimized the system using genetic algorithm. Ahmadi et al. [8] optimized a hybrid energy production system based on exergy of the process. The system contained a gas turbine as the principal driver for generation of the electricity, heat and home-made warm water, and chilling application. They considered the exergy efficiency and the total cost of the system as two objective functions and applied a multi-objective evolutionary optimization to find the best parameters to design the system. Ahmadi et al. [9] evaluated a new combined hybrid system for residential buildings after then optimized the system in terms of energy and exergy efficiencies. Their introduced cycle consisted of a heat recycling unit, an ORC system, a PEM electrolyzer, an internal water heater, and a repulsive chilling cycle. The system was installed in a residential building in Canada. Ozturk and Dincer [10] conducted a thermodynamic analysis on an integrated solar energy tower and a charcoal gas production system for hybrid production. Khalid et al. [11] proposed a combined system based on the renewable energy, including a wind turbine and solar photovoltaic cells. They obtained $25 \%$ energy and $26.8 \%$ exergy efficiencies and estimated a $1523 \mathrm{~kg}$ hydrogen production, annually. Acar and Dincer [12] studied a photoelectrochemical system of hydrogen production, experimentally. The purposed system designed not only to produce hydrogen through water electrolysis, but it also intended to produce valuable chemicals, such as chlorine and $\mathrm{NaOH}$. The reported hydrogen production rates using this system were $145 \mathrm{~mol} / \mathrm{h}$ and $295 \mathrm{~mol} / \mathrm{h}$, with and without a solar radiation intensity of $1200 \mathrm{~W} / \mathrm{m}-2$, respectively. Baniasadi [13] studied simultaneous production of hydrogen and distilled water from saline water based on splitting of the solar spectrum. Their reported results demonstrated that the proposed system can increase the water and hydrogen production rate up to 1.6 times. Islam et al. [14] developed and analyzed a solar and geothermal energy-based hybrid energy system. The system was comprised of two power turbines, a drying system, two thermal energy-saving systems, a heat pump for space heating, and an absorption chiller. The results of their study showed that the energy and exergy efficiencies of the system are $51 \%$ and $62 \%$, respectively, which both are considerable values.

The aforementioned contents demonstrate that good researches have been carried out around hybrid systems, using renewable energy. However, conducted studies are not sufficient and deeper information and investigations are required in this area. It seems that limited studies have been carried out to investigate and optimize a hybrid system to produce hydrogen as well as power and chilling, using renewable energy systems, solar energy in particular. At this work, a combined solar energy system is thermoeconomically analyzed and optimized for the hydrogen production purpose. An evacuated tube collector is used in order to collect the solar energy as the input energy of the system. The PSO algorithm is used to optimize two opposite objective functions, i.e. total costs and exergy efficiency of the system, simultaneously. For the first time in this paper, the described system is optimized using the PSO optimization algorithm. The use of the PSO algorithm for single-objective and multi-objective optimization to solve unsophisticated problems reduces the model running time compared to the genetic algorithm. The combination of MATLAB and REFPROP software is used in order to simulate the system performance. The PSO algorithm is also implemented using MATLAB software. 


\section{SYSTEM DESCRIPTION}

An integrated multifunctional energy production system, which contains four main parts and each part with various components, is shown in Fig. 1. The main parts include an ETC, an ORC, an absorption chiller, and a polymer electrolyte membrane electrolyzer. Hydrogen is produced by the PEM catalyzer. The system design parameters are presented in Table 1. Among all system components, solar collector is of paramount importance as it plays the crucial role of absorbing solar energy, converting it to heat, and transferring the resulted thermal energy to the ORC working fluid. Low efficiencies of the solar collectors, which are the obvious outcomes of the lowtemperature thermodynamic cycles, are the limiting factors in their extensive application. The most significant advantage of the collector utilized in the present study is that it can absorb the sun rays at any radiation angle. Even on the cloudy days that sunlight shines with different angles, ETC can collect solar energy, considerably. This feature of ETC can result in the enhancement of the system's efficiency. Because of the suitable thermodynamic properties of R245fa for the operating conditions of the system, this fluid is selected as the working fluid in the system performance simulation. The major assumptions of the system simulation are listed as follows:

1. System simulation is based on the steady-state assumption.

2. Pressure drops in evaporator, heat exchangers and pipes are not considered.

3. The process inside the valves is taken into account as isenthalpic.

4. The states of the working fluid at the evaporator outlet and the condenser outlet are considered as saturated liquid and saturated vapor, respectively.

5. The kinetic and potential exergies are considered to be zero.

6. The ORC turbine and pump have constant isentropic efficiencies.

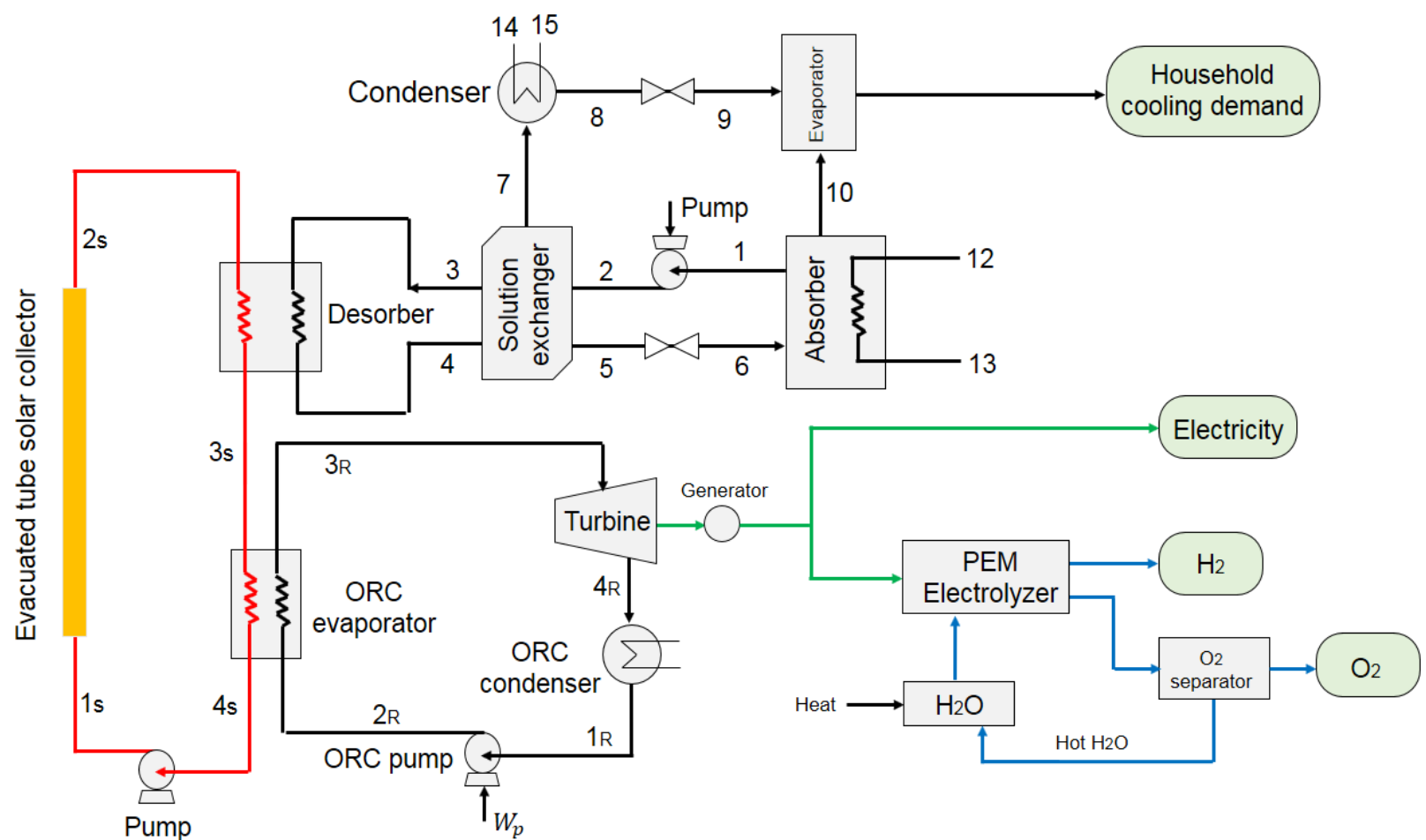

Figure 1. The schematic diagram of the combined hybrid system with an ETC 
Table 1. Input data

\begin{tabular}{|c|c|c|}
\hline Parameter & Value & Unit \\
\hline Flat plate collector area $\left(A_{p}\right)$ & 4000 & $\mathrm{~m}^{2}$ \\
\hline Collector inlet temperature & 27 & ${ }^{\circ} \mathrm{C}$ \\
\hline Mass flow rate of the collector & 5 & $\mathrm{~kg} / \mathrm{s}$ \\
\hline Incident solar power $(I)$ & 500 & $\mathrm{~W} / \mathrm{m}^{2}$ \\
\hline Optical efficiency $\left(\eta_{0}=\mathcal{T} \alpha\right)$ & 0.84 & $(-)$ \\
\hline Maximum temperature of the ORC $\left(T_{3 R}\right)$ & 50 & ${ }^{\circ} \mathrm{C}$ \\
\hline ORC evaporator inlet water temperature $\left(T_{3 s}\right)$ & 55 & ${ }^{\circ} \mathrm{C}$ \\
\hline The ratio of ORC output electricity feed to PEM & 0.5 & $(-)$ \\
\hline
\end{tabular}

\section{METHODOLOGY}

\section{Evacuated Tube Collector}

In the presence of the solar radiation, the temperature of the water circulating in the collector rises. This hot water can feed the ORC. The water enters the solar collector with a temperature of $T_{1 s}$ and continues to absorb energy to reach the temperature of $\mathrm{T}_{2 \mathrm{~s}}$. So, the heat absorbed by the fluid can be written as:

$$
\dot{Q}_{u}=\dot{m}_{c o l} C_{p}\left(T_{2 s}-T_{1 s}\right)
$$

where, $\mathrm{C}_{\mathrm{p}}, \mathrm{T}_{\mathrm{s}}, \mathrm{T}_{2 \mathrm{~s}}$, and $\mathrm{m}_{-}{ }_{-} \mathrm{col}$ are the specific heat at constant pressure, the outlet and inlet water temperatures, and mass flow rate of the collector, respectively. The heat provided by the ETC can be modified as Eq. (2), by including the heat loss of the collector [15]:

$$
\dot{Q}_{u}=W F_{R}\left[\left(S-U_{l}\left(T_{f}-T_{0}\right)\right)\right.
$$

In Eq. (2), $\mathrm{T}_{\mathrm{f}}$ is the collector working fluid average temperature and $\mathrm{T}_{0}$ is the surrounding environment temperature of. $\mathrm{S}$ is the solar radiation intensity $(\mathrm{S}=\mathrm{I}) . \mathrm{F}_{\mathrm{R}}$ in the above equation is the heat loss factor that is written as:

$$
F_{R}=\frac{1 / U_{l}}{W\left[\frac{1+\frac{U_{l}}{C_{b}}}{U_{l}\left[d+(W-d) F^{\prime}\right]}+\frac{1}{C_{b}}+\frac{1}{h_{f . i} \pi d}\right]}
$$

where, $F^{\prime}$ is the collector efficiency that is considered to be 0.96 in this paper, and $U_{l}$ is the collector total loss coefficient that equals to $1.15 \mathrm{~W} \mathrm{~m}-2 \mathrm{~K}-1$ [15].

$Q_{\mathrm{L}}$ at the room temperature of $T_{0}$ is calculated as follow:

$$
Q_{L}=U_{l}
$$

The solar collector's energy efficiency is given by the following equation [15]:

$$
\eta=\frac{\dot{m}_{c o l} C_{p f}\left(T_{2 s}-T_{1 s}\right)}{I A_{P}}
$$

where $C_{p f}$ indicates the specific heat capacity, $A_{\mathrm{p}}(=2 \mathrm{DL})$ is the collector area and $\dot{m}_{c o l}$ is the fluid mass flow rate of the collector. The expression $\mathrm{D}$ also indicates the collector diameter.

\section{Organic Rankine Cycle}

As shown in the Fig. 1, warm water enters the ORC evaporator at point $3 \mathrm{~s}$ and transfers its heat to the organic fluid. The energy conservation equation of the ORC can be stated as follows at a steady-state: [16]: 


$$
\dot{m}_{c o l}\left(h_{3 s}-h_{4 s}\right)=\dot{m}_{2 R} h_{2 R}-\dot{m}_{3 R} h_{3 R}
$$

In this equation, $h_{3 \mathrm{~s}}, h_{4 \mathrm{~s}}, h_{2 \mathrm{R}}$, and $h_{3 \mathrm{R}}$ are the evaporator inlet water enthalpies of ORC, collector pump inlet water, evaporator inlet working fluid of ORC, and the evaporator outlet working fluid of ORC, respectively. Relationships describing other parts of the ORC including its turbine, condenser, and pump are shown in Eqs. (7) to (9), respectively. $\eta_{\text {is,pump }}$ is the isentropic efficiency of the pump.

$$
\begin{gathered}
\dot{W}_{T}=\dot{m}_{3 R}\left(h_{3 R}-h_{4 R}\right) \\
\dot{m}_{\text {cooling water }}\left(h_{\text {out } ; \text { cooling }}-h_{\text {in;cooling }}\right)=\dot{m}_{1 R}\left(h_{1 R}-h_{4 R}\right) \\
\eta_{\text {is,pump }}=\frac{h_{2 R s}-h_{1 R}}{h_{2 R}-h_{1 R}}
\end{gathered}
$$

\section{PEM Electrolyzer}

In the present study, hydrogen is considered as an energy carrier and the research goal is to devise an optimized system with the optimum conditions for the hydrogen production. For this purpose, a PEM electrolyzer is applied to the system (Fig. 1). The PEM electrolyzer uses the electricity provided by the ORC in order to electrolyze the water and produce oxygen and hydrogen. First, liquid water enters the heat exchanger at the room temperature and is heated to reach the temperature of the PEM electrolyzer, i.e. about $363 \mathrm{~K}$. Then, it flows to the electrolyzer. After the electrolysis process, the produced hydrogen leaves the cathode, rejecting its heat to the environment and cooling down to the room temperature. Meanwhile, a mixture of oxygen and unreacted water leaves the anode. The produced oxygen molecules separate from the water and the remained water returns to the cycle to be used in the hydrogen production process again.

\section{Absorption Chiller}

Principles of mass conservation and the first and the second laws of thermodynamics are used to evaluate the behavior of the absorption chiller. The equations describing these principles for the laminar flow is as follows: [17]:

$$
\begin{gathered}
\sum \dot{m}_{\text {in }}=\sum \dot{m}_{\text {out }} \\
\sum(\dot{m} x)_{\text {in }}=\sum(\dot{m} x)_{\text {out }}
\end{gathered}
$$

where, $\dot{m}$ is the working fluid mass flow rate and $\mathrm{x}$ is the mass concentration of $\mathrm{Li}-\mathrm{Br}$ in the solution. Total energy equilibrium for each component of the absorption chiller is calculated by the following equation:

$$
\dot{Q}-\dot{W}=\sum \dot{m}_{\text {out }} h_{\text {out }}-\sum \dot{m}_{\text {in }} h_{\text {in }}
$$

Also, chilling rate of the absorption chiller can be calculated by:

$$
\dot{Q}_{\text {in }}=\dot{m}_{9}\left(h_{10}-h_{9}\right)
$$

\section{Exergy Analysis}

Exergy, as a thermodynamic term, is defined as the maximum useful force that can be achieved through a system thermodynamic exchange process. Without the effects of nuclear, magnetic field, electrical and surface tension, it can be classified into four main parts of physical, chemical, potential, and kinetic exergy. Therefore, exergy can be calculated by the following equation: 


$$
e x=e x_{c h}+e x_{p h}+e x_{p t}+e x_{k n}
$$

In the situation where the velocity and height changes are negligible, the exergies of potential and kinetic can be ignored. Furthermore, physical and thermodynamic exergies depend on temperature and pressure, noticeably. Physical exergy can be defined as the maximum useful work obtained if the system interacts with an equilibrium state. To calculate thermophysical exergy, the following simple relationship can be used:

$$
e x_{p h}=\left(h-h_{\circ}\right)-T_{\circ}\left(s-s_{\circ}\right)
$$

where ${ }^{\circ}$ denotes environment conditions.

The chemical exergy equals to the maximum possible work which can be obtained by moving the system toward an equilibrium with a reference environment [18]. Chemical exergy is related to changes in the chemical mixture of a system from its chemical equilibrium and should be concerned in a few processes such as combustion and other important chemical reactions. Chemical exergy of a gaseous mixture is calculated as:

$$
e x_{c h}=\sum x_{k} e x_{c h}^{k}+R T_{\circ} \sum x_{k} \ln \left(x_{k}\right)
$$

Regarding the above equations, hydrogen exergy is calculated by [19]:

$$
\dot{e x} \dot{H}_{H_{2}}=\dot{m}_{H_{2}}\left(e x_{p h}+e x_{c h}\right)_{H_{2}}
$$

where $\dot{m}_{\mathrm{H} 2}$ is the hydrogen mass flow rate $(\mathrm{kg} / \mathrm{s})$. The physical exergy term $\left(e x_{p h}\right)$ is calculated by Eq. (15). Also, the chemical exergy term $\left(e x_{c h}\right)$ can be obtained according to the following equation:

$$
e x_{c h}=\frac{253153}{M_{H_{2}}}
$$

where $M_{H 2}$ is the molar mass of hydrogen $(\mathrm{kg} / \mathrm{kmol})$. Taking the first and the second laws of thermodynamics into account, the following equation is derived for exergy equilibrium [20]:

$$
\dot{E} x_{Q}+\sum \dot{m}_{i n} \mathrm{ex}_{\mathrm{in}}=\sum \dot{m}_{\text {out }} \mathrm{ex}_{\text {out }}+\dot{E} X_{W}+\dot{E} X_{D}
$$

where $\dot{E} x_{Q}, \dot{E} X_{W}$, and $\dot{E} X_{D}$ refer to heat exergy state, work exergy rate, and exergy loss rate, respectively.

\section{Economic Analysis}

Economic modeling mainly aims to calculate and analyze the final cost of a system. There are different methods that can determine costs of equipment supplement based on the design parameters of a system. Bejan and Moran [21] introduced many useful functions to obtain equipment costs of a thermal system. Their introduced functions were able to estimate the general equipment costs, effectively, with respect to the size of the components. Table 2 presents cost functions of the hybrid system components, according to the design parameters [22], [23]. In order to calculate the cost rate of each device $(\dot{Z})$ in $\$ / \mathrm{h}$, purchase equipment cost of that device can be used as following [24]:

$$
\dot{Z}_{K}=\frac{Z_{k} \times C R F \times \varphi}{N \times 3600}
$$

in which $Z_{k}$ is the purchasing cost of the kth component, CRF is the capital recovery factor, $\mathrm{N}$ is the number of annual operational hours of the power plant, and $\varphi$ stands for the operation and maintenance factor which is equal to 1.06 in most of the cases [25]. 
Journal of Thermal Engineering, Research Article, Vol. 7, No. 4, pp. 746-760, May, 2021

Table 2. Components cost functions of the integrated hybrid system [13], [26].

\begin{tabular}{|c|c|}
\hline Component & Cost function \\
\hline ORC evaporator & $Z_{\text {ev }}=309.14\left(A_{\text {ev }}\right)^{0.88}$ \\
\hline ORC pump & $Z_{\text {pump }}=200\left(\dot{W}_{\text {pump }}\right)^{0.65}$ \\
\hline ORC turbine & $Z_{\text {tur }}=4750\left(\dot{W}_{\text {tur }}\right)^{0.6}$ \\
\hline ORC condenser & $Z_{\text {cond }}=516.62\left(A_{\text {cond }}\right)^{0.6}$ \\
\hline Absorption chiller & $Z_{\text {chiller }}=1144.3\left(\dot{Q}_{\text {ev }}\right)^{0.67}$ \\
\hline Flat plate collector & $Z_{\text {flatplate }}=235\left(A_{\text {flatplate }}\right)$ \\
\hline Proton exchange membrane $(\mathrm{PEM})$ electrolyzer & $Z_{P E M}=1000 \dot{W}_{P E M}$ \\
\hline
\end{tabular}

\section{Optimization}

To the precise assessment of the system and investigate the impact of the system design parameters on the thermoeconomic performance of the system, two objective functions are considered to be exergy efficiency and total cost rate, respectively. In the multi-objective optimization, the first objective function is defined as:

$$
\psi=\frac{\dot{m}_{\mathrm{H}_{2}} E x_{\mathrm{H}_{2}}+\dot{E} x_{\text {cooling }}+\dot{E} x_{\text {electricity }}}{\dot{E} x_{\text {in;collector }}}
$$

where $\psi$ is the system exergy efficiency. In addition, $\dot{E} x_{i n, \text { collector }}$ is the rate of input exergy received by the collector from the sun. Eq. (22) is used to calculate the input exergy rate of the solar collector if the sun is assumed as an infinite thermal resource. Furthermore, $\dot{E} x_{\text {electricity }}$ corresponds to the output electrical exergy of the system, which is equivalent to a portion of the electricity fed to the external users. In addition, $\dot{E} x_{\text {cooling }}$ can be obtained based on the chilling capacity (Eq. (23)) and $E x_{H_{2}}$ is the hydrogen exergy per mass unit, which is considered as $118.050 \mathrm{~kJ} \mathrm{~kg}-1$ [18].

$$
\begin{gathered}
\dot{E} x_{\text {in } ; \text { collector }}=\eta_{\circ} I A_{p}\left(1-\frac{T_{\circ}}{T_{\text {sun }}}\right) \\
\dot{E} x_{\text {cooling }}=\dot{Q}_{e v}\left(1-\frac{T_{\circ}}{T_{\text {sun }}}\right)
\end{gathered}
$$

In Eq. (22), $T_{\text {sun }}$ is the sun apparent temperature (equals to $75 \%$ of the sun black body temperature) [26].

The second objective function can be written as Eq. (24), according to the cost rate of the components [27]:

$$
\dot{C}_{\text {total }}=\dot{Z}_{\text {flatplate }}+\dot{Z}_{P E M}+\dot{Z}_{\text {pump }, R}+\dot{Z}_{\text {ev }, R}+Z_{\text {tur }, R}+Z_{\text {cond }, R}+Z_{\text {chiller }}
$$

Decision-making variables are identified through analyzing the system parameters and the impact of these parameters on two objective functions. The decision variables and their feasible range for multi-objective optimization are shown in Table 3.

Table 3. Feasible range of the decision variables

\begin{tabular}{|c|c|c|c|}
\hline Decision variables & Lower bound & Upper bound & Limitation \\
\hline Inlet temperature of the ORC turbine $\left({ }^{\circ} \mathrm{C}\right)$ & 44 & 54 & Thermodynamic \\
\hline Generator outlet temperature $\left({ }^{\circ} \mathrm{C}\right)$ & 55 & 65 & Thermodynamic \\
\hline Area of the Flat plate collector $\left(\mathrm{m}^{2}\right)$ & 3000 & 8000 & Commercial \\
\hline Collector water mass flow rate $(\mathrm{kg} / \mathrm{s})$ & 3 & 8 & Technical \\
\hline Solar radiation level $\left(\mathrm{W} / \mathrm{m}^{2}\right)$ & 400 & 600 & Environmental \\
\hline
\end{tabular}


Journal of Thermal Engineering, Research Article, Vol. 7, No. 4, pp. 746-760, May, 2021

\section{RESULTS AND DISCUSSION}

In this section, the results of the integrated system analysis are reports. Furthermore, results of the parametric analysis according to the defined objective functions and optimization of the system based on the multiobjective PSO algorithm are discussed. Thermodynamic properties for the different points of the integrated system are presented in Table 4.

Table 4. Different points thermodynamic properties for R245fa fluid

\begin{tabular}{|c|c|c|c|c|c|c|}
\hline Point & $\mathbf{E x}(\boldsymbol{k} \boldsymbol{W})$ & $\mathbf{s}\left(\frac{\boldsymbol{k} \boldsymbol{j}}{\boldsymbol{k g} \boldsymbol{K}}\right)$ & $\mathbf{h}\left(\frac{\boldsymbol{k j}}{\boldsymbol{k g}}\right)$ & $\mathbf{T}\left({ }^{\circ} \boldsymbol{C}\right)$ & $\mathbf{P}(\boldsymbol{k P a})$ & $\mathbf{m}\left(\frac{\boldsymbol{k g}}{\boldsymbol{s}}\right)$ \\
\hline $\mathbf{1 s}$ & 0.170 & 0.39 & 113.3 & 27 & 200 & 5 \\
\hline $\mathbf{2 s}$ & 16.910 & 1.02 & 315.8 & 75.42 & 180 & 5 \\
\hline $\mathbf{3 s}$ & 6.488 & 0.77 & 230.4 & 55 & 180 & 5 \\
\hline $\mathbf{4 s}$ & 0.129 & 0.39 & 111.2 & 26.5 & 180 & 5 \\
\hline $\mathbf{1 R}$ & 0.018 & 1.10 & 227.70 & 26.5 & 96.49 & 2.687 \\
\hline $\mathbf{2 R}$ & 0.100 & 1.10 & 228.10 & 26.8 & 217.10 & 2.687 \\
\hline $\mathbf{3 R}$ & 14.320 & 1.67 & 413.20 & 50.0 & 212.70 & 2.687 \\
\hline $\mathbf{4 R}$ & 1.885 & 1.68 & 401.50 & 27.0 & 98.46 & 2.687 \\
\hline $\mathbf{1}$ & 1.783 & 0.20 & 93.10 & 34.6 & 0.68 & 8.693 \\
\hline $\mathbf{2}$ & 5.907 & 0.20 & 97.20 & 34.6 & 7.42 & 8.693 \\
\hline $\mathbf{3}$ & 8.758 & 0.40 & 159.00 & 67.6 & 7.42 & 8.693 \\
\hline $\mathbf{4}$ & 12.490 & 0.47 & 185.60 & 80.0 & 7.42 & 8.614 \\
\hline $\mathbf{5}$ & 9.463 & 0.26 & 123.20 & 45.62 & 7.42 & 8.614 \\
\hline $\mathbf{6}$ & 27.610 & 0.20 & 123.20 & 35.6 & 0.68 & 8.614 \\
\hline $\mathbf{7}$ & 167.300 & 8.48 & 2649.30 & 80.0 & 7.42 & 0.079 \\
\hline $\mathbf{8}$ & 2.708 & 0.57 & 168.00 & 40.1 & 7.42 & 0.079 \\
\hline $\mathbf{9}$ & -8.383 & 0.61 & 168.00 & 1.5 & 0.68 & 0.079 \\
\hline $\mathbf{1 0}$ & -164.400 & 9.11 & 2503.30 & 1.5 & 0.68 & 0.079 \\
\hline $\mathbf{1 1}$ & 1.783 & 0.20 & 93.10 & 34.6 & 0.68 & 8.693 \\
\hline $\mathbf{1 2}$ & 0.000 & 0.30 & 83.90 & 20 & 100 & 7.187 \\
\hline $\mathbf{1 3}$ & 1.584 & 0.50 & 146.70 & 35 & 100 & 7.187 \\
\hline $\mathbf{1 4}$ & 0.000 & 0.30 & 83.90 & 20 & 100 & 4.703 \\
\hline $\mathbf{1 5}$ & 0.719 & 0.44 & 125.80 & 30 & 100 & 4.703 \\
\hline & & & & & \\
\hline
\end{tabular}

\section{Parametric analysis}

In this section, effects of the five decision variables on system performance are analyzed. Fig. 2 shows the impact of altering mass flow rate of the collector on the two optimization objective functions. The results imply that increasing the collector mass flow rate from $3 \mathrm{~kg} / \mathrm{s}$ to $8 \mathrm{~kg} / \mathrm{s}$ can increase the exergy efficiency and the system total cost rate. It means that the values of both criteria functions increase with the collector mass flow rate increment. Fig. 3 illustrates changes in the output power, hydrogen production rate, and chilling capacity of the system with variation of the collector mass flow rate. According to this figure, increasing mass flow rate of the collector increases the hydrogen production rate, power generation, and chilling capacity while the most noticeable growth is observed for power and hydrogen generation. Cause of the relatively poor improvement in the chilling capacity is that increasing the collector mass flow rate from $3 \mathrm{~kg} \mathrm{~s}-1$ to $8 \mathrm{~kg} \mathrm{~s}-1$ results in a decrease in the collector output. This change in the fixed output of the generator leads to an increase in capacity of the absorption chiller. Fig. 4 shows the impact of ORC turbine inlet temperature $\left(T_{3 \mathrm{R}}\right)$ on the objective functions. As it can be seen from Fig. 4, increment of T3R can improve the exergy efficiency from $1.1 \%$ to $2 \%$ and the total cost rate of the system from $21.5 \$$ h- 1 to $25.5 \$ \mathrm{~h}-1$. Fig. 5 shows that chilling capacity is not affected by the ORC turbine inlet temperature since the chilling capacity remains nearly constant as $T_{3 \mathrm{R}}$ increases. Power generation is not changed considerably with variation in $T_{3 \mathrm{R}}$, too. 
Nevertheless, increasing $T_{3 \mathrm{R}}$ improves the hydrogen production rate. The system performance also depends on the solar radiation level and the required amount of supplementary heat. Hence, the solar radiation is chosen as one of the main decision variables. Another reason for this selection is that the system works only based on solar energy and this is defined as an intrinsic feature of the designed system. Fig. 6 shows variations in the power generation, chilling capacity, and system's exergy efficiency with change in the solar radiation level. According to the Fig. 6, higher solar radiation level decreases the exergy efficiency due to an increment in input heat of the system. Furthermore, increasing the solar radiation decreases the chilling capacity. However, it does not influence the power generation, considerably. Fig. 7 indicates that extending the collector area reduces the total exergy efficiency. On the contrary, it dramatically increases system total cost rate. It means that increasing the collector area has a negative impact on both the efficiency and cost of the system. Effect of the collector area change on the outputs of the system is shown in Fig. 8. The figure illustrates that extension of the collector area declines chilling capacity of the system and increases the exergy losses. Although, the generated electricity is not altered, significantly. The ORC evaporator inlet temperature $\left(T_{3 \mathrm{~s}}\right)$ is another key design parameter of the system. Fig. 9 depicts the effect of $T_{3 \mathrm{~s}}$ change on the exergy efficiency and total cost rate. Fig. 9 shows that increasing $T_{3 \mathrm{~s}}$ from $55^{\circ} \mathrm{C}$ to $65{ }^{\circ} \mathrm{C}$ reduces the system total exergy efficiency considerably. Also, the total system cost rate increases as $T_{3 \mathrm{~s}}$ rises. The effect of $T_{3 \mathrm{~S}}$ on chilling capacity, power generation, and the rate of hydrogen production is shown in Fig. 10. According to the Fig. 10, altering $T_{3 \mathrm{~S}}$ does not affect the hydrogen and electricity production noticeably, while it enhances the chilling capacity.

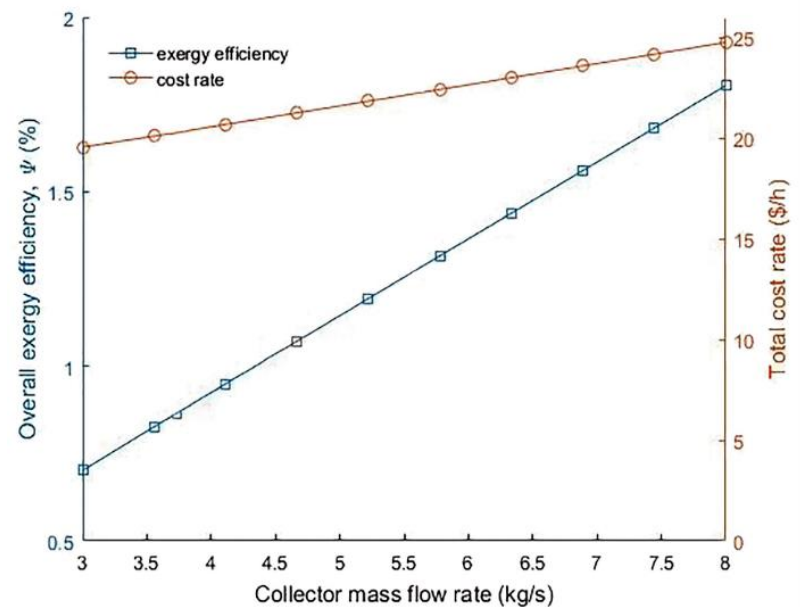

Figure 2. Impact of the collector's water mass flow rate on the objective functions

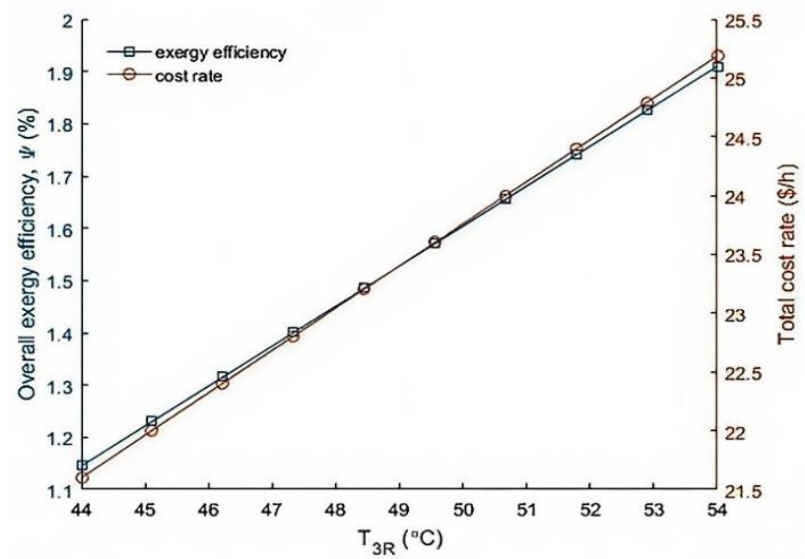

Figure 4. Changes in the system output with altering the collector's water mass flow rate

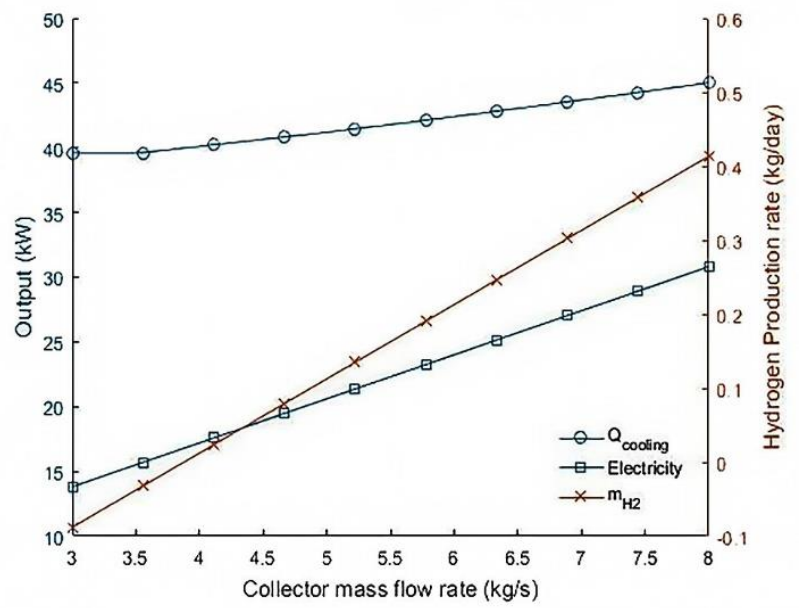

Figure 3. Changes in the system output with altering the collector mass flow rate

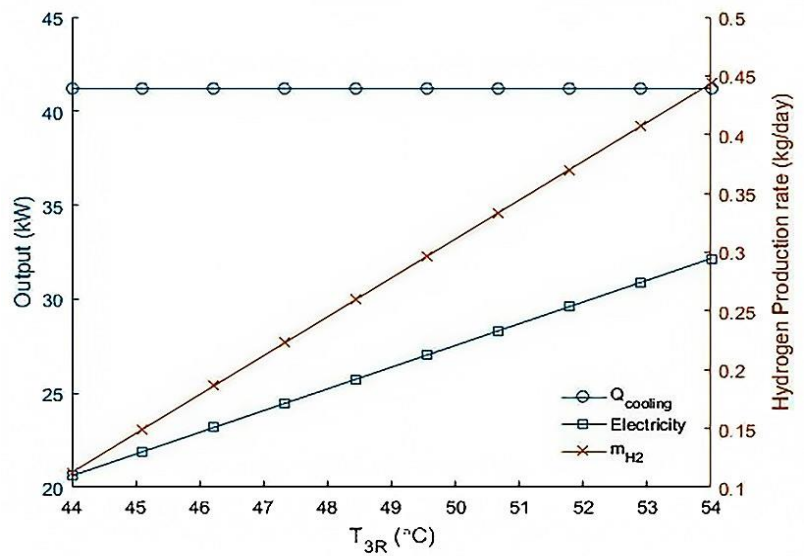

Figure 5. Impact of the organic Rankine cycle inlet temperature on the objective functions 


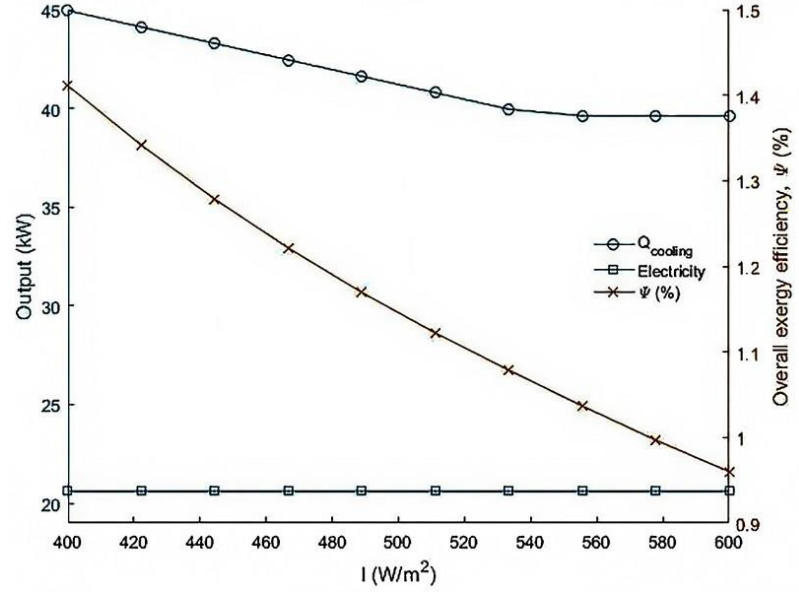

Figure 6. Impact of turbine inlet temperature on the system output

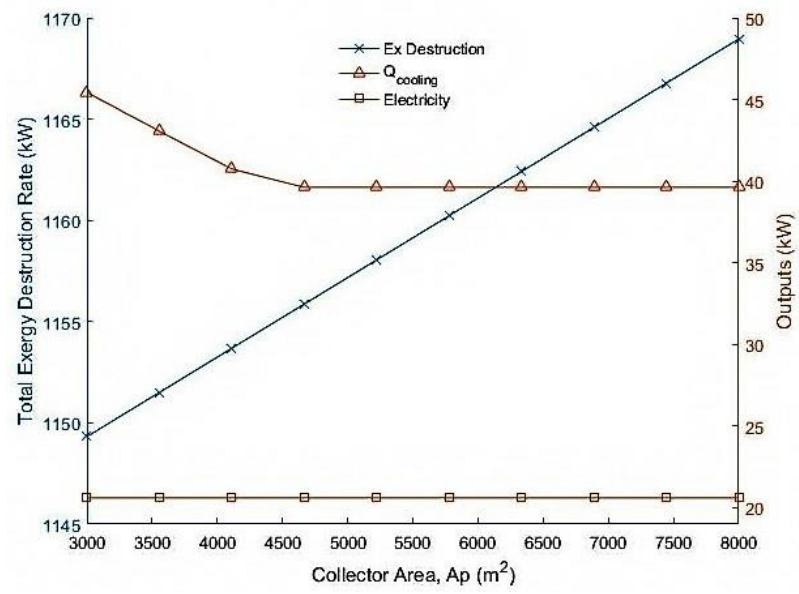

Figure 8. Impact of the collector area on the objective functions

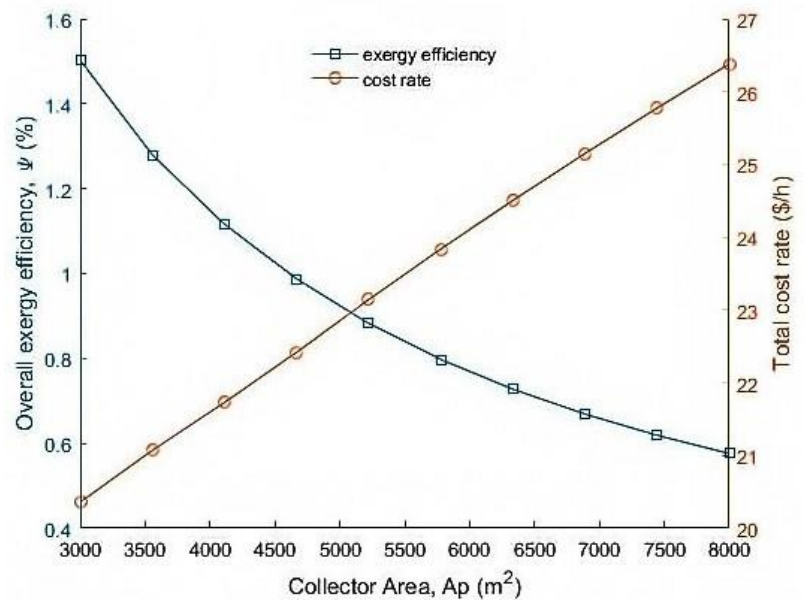

Figure 7. Impact of solar radiation on the total exergy efficiency, chilling capacity, and power generation

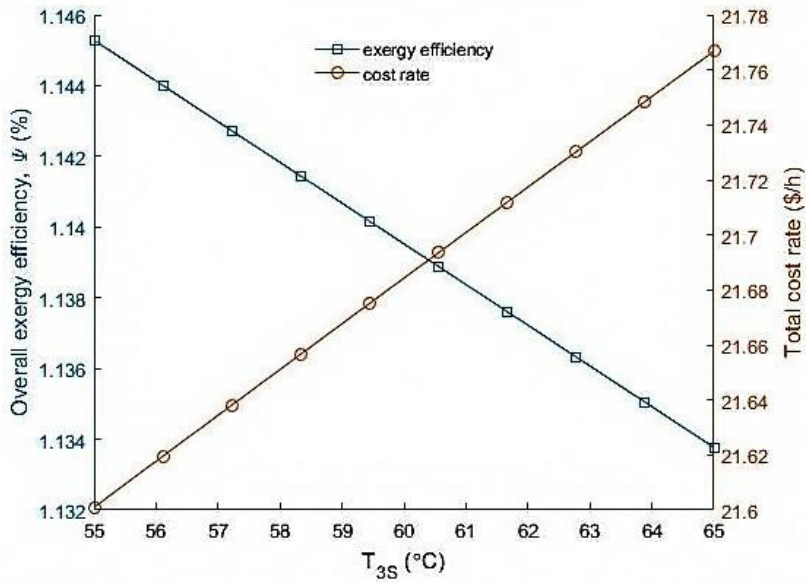

Figure 9. Impact of the collector area on total exergy loss, chilling capacity, and power generation

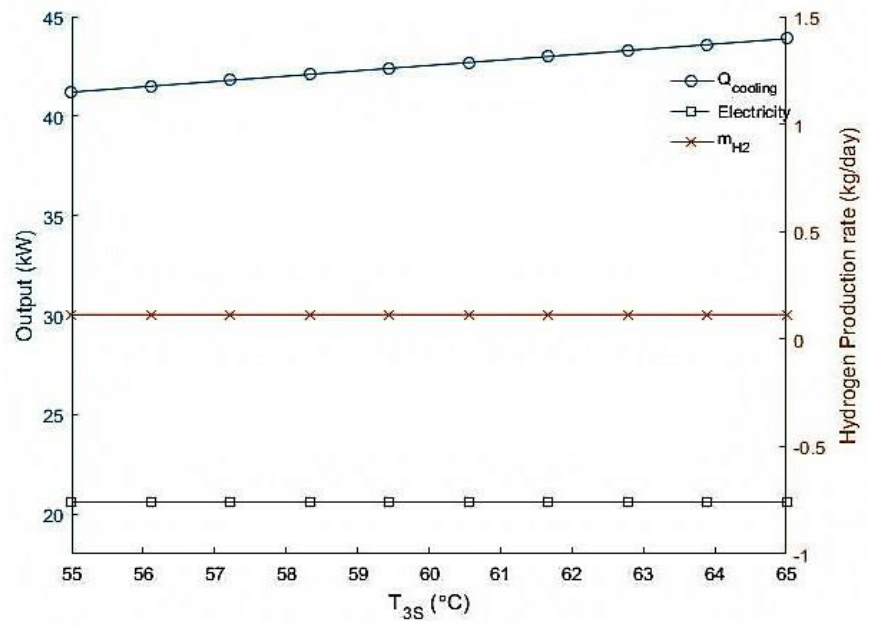

Figure 10. Changes in objective functions with altering ORC evaporator inlet temperature 


\section{Optimization results}

Ten iterations are performed to achieve the most precise optimal conditions for the system operation. Results of the 10 iterations are summarized in Table 6. In order to analyze and optimize the hybrid system, the average values of the results in Table 5 are calculated which outlined in Table 6 . As it can be observed from Table 6 , system exergy efficiency is $2.2564 \%$, that is almost low in comparison to other energy systems. The reason of the low exergy efficiency is that the energy obtained from the sun at higher temperatures is converted into the other forms of energy at lower temperatures, so a great exergy loss occurs during the total process. Also, the total cost rate of the system is $21.6656 \$ / \mathrm{h}$. Table 7 shows the average results of the 10 iterations for the five decision variables.

Table 5. Multi-objective optimization results for 10 iterations

\begin{tabular}{|c|c|c|c|c|c|c|c|c|c|c|}
\hline Parameter & $\mathbf{1}$ & $\mathbf{2}$ & $\mathbf{3}$ & $\mathbf{4}$ & $\mathbf{5}$ & $\mathbf{6}$ & $\mathbf{7}$ & $\mathbf{8}$ & $\mathbf{9}$ & $\mathbf{1 0}$ \\
\hline Output electricity $(\mathrm{kW})$ & 19.4706 & 25.126 & 21.6832 & 30.9692 & 25.967 & 16.0273 & 28.5795 & 27.6684 & 20.061 & 26.8881 \\
\hline Cooling capacity $(\mathrm{kW})$ & 46.0224 & 45.8376 & 46.2372 & 49.1675 & 46.0317 & 46.5222 & 49.1675 & 46.6132 & 45.9602 & 49.1675 \\
\hline Hydrogen production rate $(\mathrm{kg} / \mathrm{s})$ & 0.074241 & 0.23619 & 0.13865 & 0.41228 & 0.2608 & 0.022456 & 0.34385 & 0.31098 & 0.091543 & 0.29542 \\
\hline Total exergy efficiency $(\%)$ & 1.7472 & 2.3721 & 1.9898 & 2.9642 & 2.4635 & 1.3569 & 2.7007 & 2.6472 & 1.8088 & 2.5141 \\
\hline Total cost rate $(\$ / h)$ & 20.2158 & 21.952 & 20.8855 & 23.7238 & 22.2094 & 19.1152 & 22.9825 & 22.7312 & 20.3841 & 22.4561 \\
\hline
\end{tabular}

Table 6. Average results of the optimization

\begin{tabular}{|c|c|}
\hline Parameter & Value \\
\hline Output electricity $(\mathrm{kW})$ & 24.2439 \\
\hline Cooling capacity $(\mathrm{kW})$ & 47.07263 \\
\hline Hydrogen production rate $(\mathrm{kg} / \mathrm{s})$ & 0.21856 \\
\hline Total exergy efficiency $(\%)$ & 2.2564 \\
\hline Total cost rate $(\$ / h)$ & 21.6656 \\
\hline
\end{tabular}

Table 7. Average results for the five decision variables

\begin{tabular}{|c|c|c|}
\hline Decision variable & Value & Unit \\
\hline$T_{3 R}$ & 46.4916 & ${ }^{\circ} \mathrm{C}$ \\
\hline$T_{3 S}$ & 60.0104 & ${ }^{\circ} \mathrm{C}$ \\
\hline$A_{p}$ & 3000 & $\mathrm{~m}^{2}$ \\
\hline$\dot{m}_{c o l}$ & 5.5241 & $\mathrm{~kg} / \mathrm{s}$ \\
\hline$I$ & 400 & $\mathrm{~W} / \mathrm{m}^{2}$ \\
\hline
\end{tabular}

The pareto diagram for the objective functions and a spectrum of changes in the decision variables is shown in Fig. 11. As shown in the figure, increasing the system efficiency is accompanied with increase in the system final cost. It can be inferred from Fig. 11 that there is a set of optimized solutions instead of a single optimized solution, resulted from the multi-objective optimization. The optimized solution set is presented as the Pareto curve, called Pareto optimized solution set. However, a single solution is required to be defined as the final solution. The ideal point for this case is the point at that the exergy efficiency is at its highest amount and the total cost rate is at its minimum. However, the Pareto chart shows that the objective functions obey opposite trends, i.e. when the exergy efficiency is at its maximum, the total cost rate is at its maximum and vice versa. Hence, an absolute ideal point does not exist. In this circumstance, the closest point to the ideal point should be selected as the final solution. As it can be observed in Fig. 11, optimum values of the exergy efficiency and system cost rate change from $1 \%$ to $3.5 \%$ and $20 \$$ h-1 to 26 \$ h-1 on the Pareto chart, respectively. Characteristics of the selected points on the Pareto chart for 10 iterations of the developed optimization code are reported in Table 8. 
In order to derive an optimum relationship between the exergy efficiency and system cost rate, a curve is fitted on the points extracted from the multi-objective optimization problem on the Pareto chart. The obtained curve is expressed as Eq. (25). It should be mentioned that this equation is valid just for the present problem and the exergy efficiency range of $1 \%$ to $3.5 \%$.

$$
\dot{\mathrm{C}}_{\text {total }}(\psi)=-0.039377 \psi^{4}+0.39682 \psi^{3}-1.4774 \psi^{2}+5.2247 \psi+13.9325
$$

Table 8. Average property values of the points selected on the Pareto chart

\begin{tabular}{|c|c|c|c|}
\hline Point & A & B & C \\
\hline$T_{3 R}\left({ }^{\circ} \mathrm{C}\right)$ & 53.809 & 44.929 & 44.556 \\
\hline$T_{3 S}\left({ }^{\circ} \mathrm{C}\right)$ & 65 & 55 & 59.172 \\
\hline$A_{p}\left(\mathrm{~m}^{2}\right)$ & 3000 & 3000 & 3000 \\
\hline$\dot{m}_{c o l}(\mathrm{~kg} / \mathrm{s})$ & 5.9349 & 5.9807 & 3 \\
\hline$I\left(\mathrm{~W} / \mathrm{m}^{2}\right)$ & 400 & 400 & 400 \\
\hline
\end{tabular}

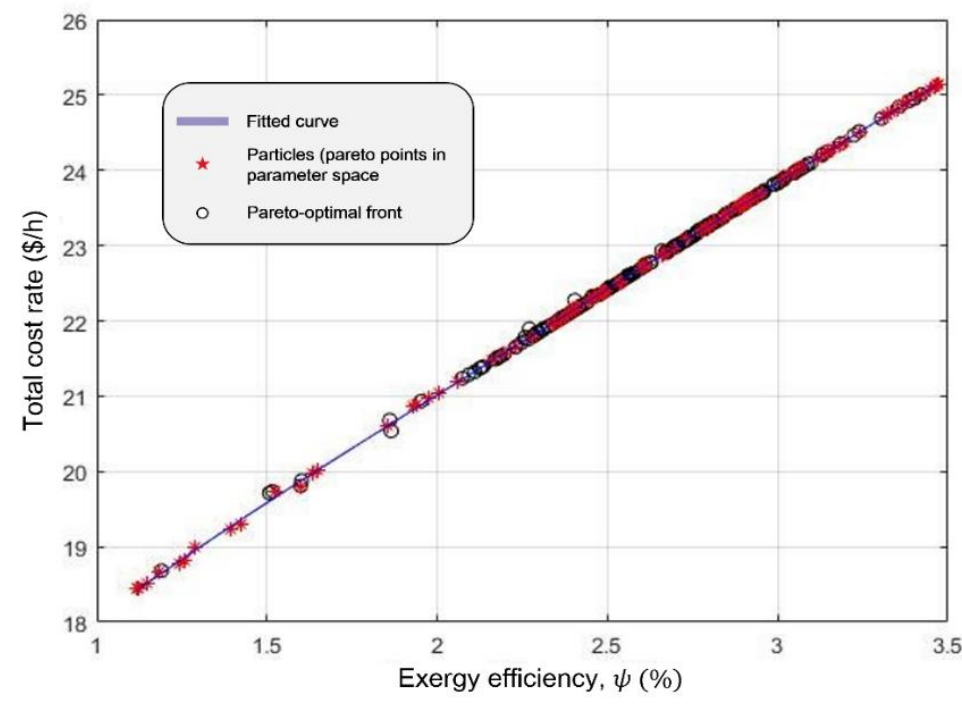

Figure 11. Pareto chart of the two objective functions based on the changes in decision variables

\section{CONCLUSION}

One of the dominant applications of the hydrogen is generating electricity using fuel cells. This results in an increment in the reliability of systems which utilize solar energy as the input energy. Therefore, methodologies that focus on the design and optimization of the systems which use renewable energies to produce hydrogen, will lead to broadening the application of these renewable energies in the future. Hence, an integrated solar energy system for hydrogen production was investigated in this research. The exergoeconomic analysis was conducted to evaluate the performance of the proposed system and the particle swarm optimization algorithm was used in order to optimize the system. Furthermore, the parametric analysis was accomplished to determine the impact of varying the design variable including generator outlet temperature, ORC turbine inlet temperature, solar radiation level, flat plate collector area, and collector water mass flow rate on the system performance. The most striking results emerged from the system evaluation are listed as follows:

- The results of the parametric analysis indicated that the increment of the mass flow rate can improve efficiency of the system from $0.5 \%$ to $2 \%$.

- The results exhibited that increasing the collector's mass flow rate improves the hydrogen production rate from $0 \mathrm{~kg} / \mathrm{s}$ to $0.41 \mathrm{~kg} / \mathrm{s}$. 
- Increasing the ORC maximum temperature improves the $\mathrm{H} 2$ production rate from $0.1 \mathrm{~kg} / \mathrm{day}$ to $0.45 \mathrm{~kg} / \mathrm{day}$. Besides, increasing the turbine inlet temperature raises the cost rate and efficiency, simultaneously, with a more considerable impact on the costs.

- The area of the collector has a considerable impact on the total cost. The larger the collector area, the more system total cost. Also, increasing the collector area had a negative impact on collector exergy efficiency.

- An increase in the turbine inlet temperature results in an increase in the exergy efficiency from $1.1 \%$ to $1.9 \%$ and total power production from $20 \mathrm{~kW}$ to $30 \mathrm{~kW}$. Furthermore, increasing this parameter raises the system's total cost rate.

- Implementation of the multi-objective optimization improves the system exergy efficiency up to $3.5 \%$.

\section{NOMENCLATURE}

\begin{tabular}{|c|c|}
\hline$A_{p}$ & area, $\mathrm{m}^{2}$ \\
\hline$\dot{C}$ & cost rate, $\$ / \mathrm{h}$ \\
\hline $\mathrm{C}_{\mathrm{p}}$ & specific thermal capacity, $\mathrm{kJ} / \mathrm{kg} \mathrm{K}$ \\
\hline$e x$ & specific exergy, $\mathrm{kJ} / \mathrm{kg}$ \\
\hline$\dot{E} x$ & exergy rate, $\mathrm{kw}$ \\
\hline $\mathrm{F}_{\mathrm{R}}$ & heat removal factor \\
\hline$F^{\prime}$ & collector efficiency factor \\
\hline$G$ & generator \\
\hline$H$ & enthalpy, $\mathrm{kJ} / \mathrm{kg}$ \\
\hline$I$ & solar radiation intensity, $\mathrm{W} / \mathrm{m}^{2}$ \\
\hline$\dot{m}_{c o l}$ & collector mass flow rate, $\mathrm{kg} / \mathrm{s}$ \\
\hline $\mathrm{Q}_{\mathrm{u}}$ & collector heat gained \\
\hline $\mathrm{Q}_{\mathrm{L}}$ & collector heat losses \\
\hline$T_{3 \mathrm{R}}$ & organic Rankine cycle inlet temperature, ${ }^{\circ} \mathrm{K}$ \\
\hline$T_{3 \mathrm{~s}}$ & Inlet water temperature of $\mathrm{ORC}$ evaporator, ${ }^{\circ} \mathrm{K}$ \\
\hline $\mathrm{U}_{1}$ & overall collector loss coefficient \\
\hline$x$ & mass concentration of $\mathrm{Li}-\mathrm{Br}$ \\
\hline$Z$ & Purchase equipment cost, \$ \\
\hline$\dot{Z}$ & cost rate, $\$ / \mathrm{h}$ \\
\hline$W$ & the circumferential distance between the collector, $\mathrm{m}$ \\
\hline$T_{f}$ & mean temperature of the working fluid, $\mathrm{K}$ \\
\hline$T_{0}$ & ambient temperature, $\mathrm{K}$ \\
\hline $\mathrm{D}$ & diameter of the collector, $\mathrm{m}$ \\
\hline$h_{f . i}$ & the heat transfer coefficient between the fluid and the collector wall, $\mathrm{W} /(\mathrm{m} . \mathrm{K})$ \\
\hline$C_{b}$ & synthetical conductance, $\mathrm{W} /(\mathrm{m} . \mathrm{K})$ \\
\hline $\mathrm{C}_{\mathrm{pf}}$ & the specific heat capacity, $\mathrm{kJ} /(\mathrm{kg} . \mathrm{K})$ \\
\hline$f$ & fin efficiency of straight fin \\
\hline$L$ & the length of absorber tube, $m$ \\
\hline \multicolumn{2}{|c|}{ Subscripts } \\
\hline col & collector \\
\hline cond & condenser \\
\hline ev & evaporator \\
\hline in & inlet \\
\hline is & isentropic \\
\hline $\mathrm{L}$ & loss \\
\hline out & outlet \\
\hline $\mathrm{P}$ & pump \\
\hline $\mathrm{R}$ & organic Rankine cycle \\
\hline S & solar \\
\hline
\end{tabular}


Journal of Thermal Engineering, Research Article, Vol. 7, No. 4, pp. 746-760, May, 2021

$\begin{array}{ll}\text { tur } & \text { solar } \\ \mathrm{u} & \text { utilize } \\ \circ & \text { reference state }\end{array}$

\section{Greek symbols}

$\alpha$

absorptance
operation and maintenance factor
efficiency
optical efficiency
transmittance
exergy efficiency

Abbreviations

ORC

PEM

organic Rankine cycle

CRF

proton exchange membrane

capital recovery factor

\section{REFERENCES}

[1] Luminosu, I., and Fara, L. (2005). Determination of the optimal operation mode of a flat solar collector by exergetic analysis and numerical simulation. Energy, 30, 731-747

[2] Syed, A., Izquierdo, M., Rodrígueze, P., Maidment, G., Missenden, J., Lecuona, A., Tozer, R. (2005). A novel experimental investigation of a solar cooling system in Madrid. International Journal of Refrigeration, 28, 859871

[3] Sahoo, P. K. (2008). Exergoeconomic analysis and optimization of a cogeneration system using evolutionary programming. Applied Thermal Engineering, 28, 1580-1588

[4] Yamada, N., Hoshi, A., and Ikegami, Y. (2009). Performance simulation of solar-boosted ocean thermal energy conversion plant. Energy, 34, 1752-1758, Jul. 2009.

[5] Mateus, T. and Oliveira, A. C. (2009). Energy and economic analysis of an integrated solar absorption cooling and heating system in different building types and climates. Applied Energy, 86, 949-957

[6] Molero-Villar, N., Cejudo-López, J. M., Domínguez-Muñoz, F., and Carrillo-Andrés, A. (2012). A comparison of solar absorption system configurations. Solar Energy, 86, 242-252

[7] Wang, J., Zhao, P., Niu, X., and Dai, Y. (2012). Parametric analysis of a new combined cooling, heating and power system with transcritical CO2 driven by solar energy. Applied Energy, 94, 58-64

[8] Ahmadi, P., Dincer, I., and Rosen, M. A. (2013). Energy and exergy analyses of hydrogen production via solarboosted ocean thermal energy conversion and PEM electrolysis. International Journal of Hydrogen Energy, 38,1795-1805

[9] Ahmadi, P., Dincer, I., and Rosen, M. A. (2013). Performance assessment and optimization of a novel integrated multigeneration system for residential buildings. Energy and Buildings, 67, 568-578

[10] Ozturk, M. and Dincer, I. (2013). Thermodynamic assessment of an integrated solar power tower and coal gasification system for multi-generation purposes. Energy Conversion and Management, 76, 1061-1072.

[11] Khalid, F. and Rosen, M. A. (2016). Analysis and assessment of an integrated hydrogen energy system. International Journal of Hydrogen Energy, 41, 7960-7967

[12] Acar, C. and Dincer, I. (2017). Experimental investigation and analysis of a hybrid photoelectrochemical hydrogen production system. International Journal of Hydrogen Energy, 42, 2504-2511

[13] Baniasadi, E. (2017). Concurrent hydrogen and water production from brine water based on solar spectrum splitting: Process design and thermoeconomic analysis. Renewable Energy, 102, 50-64

[14] Islam, S. and Dincer, I. (2017). Development, analysis and performance assessment of a combined solar and geothermal energy-based integrated system for multigeneration. Solar Energy, 147, 328-343

[15] Ma, L., Lu, Z., Zhang, J., and Liang, R. (2010). Thermal performance analysis of the glass evacuated tube solar collector with U-tube. Building and Environment, 45, 1959-1967

[16] Khanmohammadi, S., Ahmadi, P., Atashkari, K., and Kamali, R. K. (2015). Design and Optimization of an Integrated System to Recover Energy from a Gas Pressure Reduction Station. In Progress in Clean Energy, Cham: Springer International Publishing, 89-107

[17] Khanmohammadi, S. and Azimian, A. R. (2015). Exergoeconomic Evaluation of a Two-Pressure Level Fired Combined-Cycle Power Plant. Journal of Energy Engineering, 141, 04014014-1-04014014-13 
[18] Kotas, T. J. (1985). The exergy method of thermal plant analysis. Butterworths

[19] Wenisch A., Pladerer C., (2003). Energy Situation and Alternatives in Romania. The compagna per la Riforma Della Banca Mondiale, Vienna.

[20] Ameri, M., Ahmadi, P., and Khanmohammadi, S. (2008). Exergy analysis of a $420 \mathrm{MW}$ combined cycle power plant. International Journal of Energy Research, 32, 175-183

[21] Bejan, A., Tsatsaronis, G., and Moran, M. J. (1996). Thermal design and optimization. Wiley

[22] Genç, G., Çelik, M., and Serdar Genç, M. (2012). Cost analysis of wind-electrolyzer-fuel cell system for energy demand in Pınarbaşı-Kayseri. International Journal of Hydrogen Energy, 37, 12158-12166

[23] Peters, M. S., Timmerhaus, K. D., and West, R. E. (2003). Design and economics for chemical engineers. McGraw-Hill

[24] Khanmohammadi, S., Atashkari, K., and Kouhikamali, R. (2015). Exergoeconomic multi-objective optimization of an externally fired gas turbine integrated with a biomass gasifier. Applied Thermal Engineering, 91, 848-859

[25] Balli, O., Aras, H., and Hepbasli, A. (2008). Exergoeconomic analysis of a combined heat and power (CHP) system. International Journal of Energy Research, 32, 273-289

[26] Bejan, A., Kearney, D. W., and Kreith, F. (1981). Second Law Analysis and Synthesis of Solar Collector Systems. Journal of Solar Energy Engineering, 103, 23-28

[27] Khanmohammadi, S., Heidarnejad, P., Javani, N., and Ganjehsarabi, H. (2017). Exergoeconomic analysis and multi objective optimization of a solar based integrated energy system for hydrogen production. International Journal of Hydrogen Energy, 42, 21443-21453 